Entrevista - Diálogos Midiológicos 30

\title{
Os estudos sobre meios digitais e o risco da fragmentação na Comunicação
}

The digital media studies and the risk of fragmentation in Communication

Los estudios de medios digitales y el riesgo de la fragmentación en Comunicación

DOI $10.1590 / 1809-5844201415$

Marc Lits

Entrevista concedida a Ana Cristina Suzina*

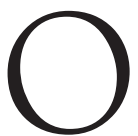

professor Marc Lits é, atualmente, o diretor da Faculdade de Ciências Econômicas, Sociais, Políticas e de Comunicação (ESPO, da sigla em francês) e presidente do polo de pesquisa em Comunicação do Instituto de Linguagem e Comunicação (ILC) da Universidade Católica de Louvaina, na Bélgica. Ele é membro da equipe de chefia de redação das revistas Hermès (Paris,

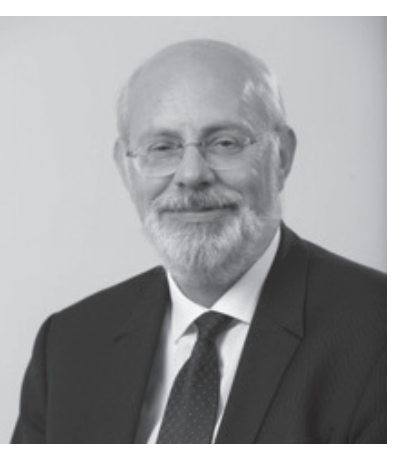

"Doutoranda em Ciências Políticas e Sociais na Universidade Católica de Lovaina, com uma pesquisa sobre mídias populares, comunitárias e alternativas no Brasil.E-mail: ana.suzina@student.uclouvain.be 
CNRS) e Recherches en Communication (UCL, Louvain-la-Neuve), e também membro do comitê científico das revistas Questions de Communication (Universidade de Lorraine), Communication \& Management, Semen.

Entre suas publicações de destaque, estão os livros Communication politique et lobbying (com Th. Koutroubas, pela editora De Boeck, 2011), Le roman policier dans tous ses états. D'Arsène Lupin à Navarro (Presses Universitaires de Limoges, 2011), Du récit au récit médiatique (De Boeck, 2008), Le vrai-faux journal de la RTBF. Les réalités de l'information (Ed. Couleur livres, 2007), Du 11 septembre à la riposte. Les débuts d'une nouvelle guerre médiatique (De Boeck / INA, 2004), La novellisation/Novelization. Du film au livre. From film to novel (com J. Baetens, pela editora Leuven University Press, 2004) e Le fait divers (com A. Dubied, pela editora P.U.F., 1999), além da coordenação de Populaire et populisme, uma compilação da revista Hermès (2009) e de Spectacularisation du politique, um número especial da revista Recherches en communication (2005).

Nesta entrevista, Lits fala de tendências da pesquisa em Comunicação na Europa, do papel das associações e redes internacionais, da formação de jovens pesquisadores e comenta suas impressões sobre os estudos de Comunicação na América Latina.

Revista Intercom - Conte um pouco sobre sua formação.

Marc Lits - Como muitos professores da área de Informação e Comunicação da minha geração, eu venho de outra disciplina, no meu caso, os estudos de Língua e Literatura Francesa. Na verdade, as pesquisas e os doutorados em Comunicação começaram a se desenvolver a partir dos anos 1970. É algo interessante no que se refere à evolução da disciplina, porque, originalmente, ela era obrigatoriamente interdisciplinar. Os colegas mais experientes de meu departamento vêm da Psicologia, do Direito, da Economia, das Letras, da Linguística, da Sociologia ou da Antropologia. Atualmente, todos os jovens colegas que nós recrutamos são titulares de um doutorado em Informação e Comunicação. A disciplina se viu, portanto, valorizada, mas 
em detrimento de uma abordagem interdisciplinar que aportava igualmente muita riqueza ${ }^{1}$.

Revista Intercom - Quais os seus principais campos de pesquisa? Lits - Eu trabalho, principalmente, com análise de mídia (imprensa, televisão, internet), estudando as produções e os conteúdos, em parceria com colegas que trabalham na análise de contextos profissionais e do quadro socioeconômico, e com outros que se dedicam aos usos e à recepção das mídias. Eu trabalho, sobretudo, com mídias informativas, mas também tenho interesse pelas produções culturais (documentários, literatura popular, séries de televisão...).

Revista Intercom - Vamos conversar um pouco sobre a produção teórica e as atuais práticas de pesquisa na Europa. Quais são as principais tendências da pesquisa em Comunicação, neste momento, no continente europeu?

Lits - Eu não tenho uma visão global das pesquisas europeias, porque, diferentemente do sistema americano (ou mais precisamente, dos Estados Unidos), as diferenças geográficas, linguísticas, culturais impedem que exista um espaço europeu único de pesquisa. De todas as formas, é possível constatar algumas tendências comuns (entre outras evidências, pela observação dos temas das teses de doutorado). A primeira dessas tendências está relacionada aos suportes. Está claro que o desenvolvimento da internet e das redes sociais constitui, ao mesmo tempo, um sucesso em termos de uso e de mercado econômico, e também um campo de estudos para os pesquisadores. O papel do Twitter nas campanhas eleitorais, a importância do Facebook nos movimentos sociais alternativos, como os Indignados na Espanha, são assuntos bastante apreciados. Mas, curiosamente, ainda que essas ferramentas técnicas permitam novos tipos de relações, é pela abordagem aos conteúdos que eles frequentemente são explorados. As análises de conteúdo e de

${ }^{1}$ O tema da emergência da disciplina de Comunicação é explorado profundamente por Marc Lits em seu artigo Comment peut-on être docteur en infocom? La résistible émergence d'une discipline dans le champ clos des sciences sociales (2011). 
discurso permanecem dominantes, ainda que outras venham despontando, porque os estudos estatísticos, por meio de programas de indexação de dados, permitem análises mais aprofundadas das informações, obtidas diretamente na internet e que, portanto, podem ser tratadas sem a necessidade de codificação anterior. Outro objeto bastante exitoso são as séries de televisão. Em tempos passados, os analistas estudavam, sobretudo, os eventos políticos e sociais relacionados à mídia, quer dizer, a informação dita nobre; hoje, com a preponderância do entretenimento nos meios de Comunicação, mas também com o aumento da legitimidade das produções populares, os pesquisadores ousam analisar produtos consumidos de maneira massiva, como as séries de televisão (algo que é muito distinto das telenovelas, que têm outro tipo de legitimidade na América do Sul e que são estudadas há muito tempo). Por outro lado, os estudos de recepção interessam cada vez mais, mesmo que ainda faltem recursos para trabalhar sobre a maneira como os usuários de mídia a consomem. Esta abordagem é feita pela observação de usuários de jogos online, com um grande desenvolvimento dos game studies.

Revista Intercom - É possível falar de especificidades da pesquisa em Comunicação no contexto francófono? De que tipo?

Lits - Mesmo se reconhecemos a diversidade de abordagens, como eu disse antes, existem tendências comuns no contexto europeu. O que é específico, no contexto francófono, é a importância das abordagens semióticas e linguísticas, considerando que os primeiros pesquisadores do campo da Comunicação, nos anos 1960, vinham dessas correntes, num momento em que a linguística estrutural dominava o campo das Ciências Humanas. Saussure foi, portanto, uma referência importante para esses pesquisadores, em seguida a linguística de Greimas (mais do que a de Peirce), ainda mais porque um dos fundadores desse campo de pesquisa, na França, foi Roland Barthes. Foi assim que, entre outras coisas, em desdobramentos da semiologia, desenvolvemos uma análise da narrativa dos meios de Comunicação, algo que praticamente não existe nas abordagens anglo-americanas. É preciso notar ainda que os soci- 
ólogos seguiam a linha de Pierre Bourdieu, que manteve sempre certo desprezo pelos meios de Comunicação, que ele considerava pouco legítimos (mesmo que ele tenha apoiado a tradução do livro fundador de Hoggart, The uses of literacy). Dessa forma, enquanto os estudos de Comunicação americanos foram construídos por sociólogos (a Teoria dos Efeitos, o Two Step Flow), os estudos de Comunicação francófonos abordavam os conteúdos midiáticos com recursos de análise que vinham da semiótica estrutural. E os principais objetos de estudo vinham dos meios impressos, sobretudo em análises sobre a cobertura de eventos políticos nos jornais considerados de alta reputação.

Revista Intercom - Existe alguma abordagem teórica recente que trouxe inovação na pesquisa em Comunicação? Quais suas contribuições?

Lits - As abordagens mais recentes estão marcadas pelas ciências cognitivas (como se pode ver no último número da revista Hermès, do CNRS, o Centro Nacional de Pesquisa Científica da França, na sigla em francês ${ }^{2}$ ), e pelas neurociências. Trata-se de um objeto de debate bastante intenso entre aqueles que pensam encontrar nessas correntes as ferramentas necessárias para fazer análises experimentais (como se faz em Psicologia cognitiva) e então se aproximar do modelo das ciências ditas "duras" (e sair das análises que se limitam, às vezes, à paráfrase ou a discursos ideologicamente marcados), e outros para quem essas abordagens são muito redutoras, porque negligenciam toda a dimensão simbólica que é essencial nos estudos de Comunicação.

Revista Intercom - Como você mencionou, a crescente introdução de tecnologias nos meios de Comunicação se converteu em um tema frequente de pesquisas. Como esse debate foi introduzido nas atividades desenvolvidas na Europa? Quais são as abordagens mais frequentes? Quais os cruzamentos possíveis com as teorias clássicas dos estudos de Comunicação?

2 http://documents.irevues.inist.fr/handle/2042/8538 
Lits - As abordagens mais tecnológicas são menos estudadas pelos pesquisadores do campo da Informação e Comunicação do que por aqueles que estão no campo da Informática e da Engenharia nas Telecomunicações. E esses dois universos, o da Ciência e Tecnologia por um lado, e o das Ciências Humanas e Sociais por outro, raramente trabalham juntos. Todos os projetos europeus, financiados pela União Europeia, se concentram quase que exclusivamente em inovações tecnológicas em pesquisa e desenvolvimento, e dificilmente têm uma dimensão de impacto social. A abordagem às novas tecnologias se faz essencialmente a partir da análise dos usos: as novas tecnologias nas campanhas eleitorais, os usuários de jogos online, o peso das redes sociais nos movimentos cidadãos, o uso de redes sociais pelos jovens...

Revista Intercom - Por outro lado, nós vemos uma série de colóquios, seminários e publicações que discutem, entre outros temas, o rádio na era digital, a Comunicação política no contexto das redes sociais etc. Seguindo essa discussão, poderíamos vislumbrar o estabelecimento de um novo campo de estudos da Comunicação dedicado aos meios digitais ou a tendência seria de ter o elemento digital como uma linha ou objeto transversal no campo da Comunicação?

Lits - É possível constatar, efetivamente, nas teses de doutorado, assim como nas publicações de artigos em revistas ou nos projetos de financiamento de pesquisa, que o aspecto digital é super dominante, ao ponto de se converter, em alguns casos, em objetos científicos específicos, eventualmente em campos de estudos próprios. Já é o caso, por exemplo, dos jogos eletrônicos, que são estudados pelos game studies, que se posicionam como um campo independente dos estudos de Comunicação ou dos estudos culturais. Nós vimos o mesmo fenômeno com a fragmentação dos estudos culturais para o surgimento dos estudos de gênero, depois os "queer" studies e outras subseções. Esse processo decorre da clássica luta pela autonomia de equipes de pesquisa no campo científico, que já não tem mais para onde inovar em termos metodológicos (entre o qualitativo, o quantitativo, as pesquisa de campo, as entrevistas e outras abordagens, todas já bem balizadas) e que se 
justificam, então, por agrupamentos em torno de novos objetos, como os jogos, as NTIC, os meios participativos... Tudo isso me parece arriscado na medida em que essa fragmentação impede, cientificamente, de inscrever as pesquisas em um contexto explicativo mais amplo (estudar os jogos participativos online, sem ter em conta outras atividades sociais e lúdicas dos jogadores, quando eles estão fazendo outras coisas além de jogar). E isso fragmenta o campo das pesquisas em Ciências Sociais, que não tem necessidade disso. Nós conhecemos a guerra entre sociólogos e antropólogos, que não ajuda em nada a construir uma disciplina forte em $\mathrm{Ci}$ ências Sociais, a partir do cruzamento entre várias abordagens metodológicas. Os estudos de Comunicação são um campo jovem, pouco reconhecido, de fronteiras tênues. Esse campo nem foi ainda totalmente legitimado e já está explodindo. Isso não é útil em termos de progresso dos conhecimentos em Ciências Sociais e tampouco favorece o desenvolvimento da disciplina.

Revista Intercom - A pesquisa latinoamericana em Comunicação é conhecida no contexto científico europeu? Você poderia citar algum aspecto mais conhecido dela nesse contexto?

Lits - Eu conheço pouco as pesquisas latinoamericanas. Mas eu tenho a impressão que existem duas tendências: uma abordagem ainda muito influenciada pela Escola de Frankfurt, de inspiração marxista e denunciadora do papel dos meios de Comunicação como suporte das classes dominantes e do poder econômico e político. Trata-se de uma abordagem bastante sociológica, de esquerda, em uma lógica de denúncia, ainda marcada pelos trabalhos de Armand Mattelart, que desempenhou um papel importante na América Latina (ligado à história política do continente sulamericano). Outra abordagem é mais sensível à dimensão cultural, e eu penso em Jesús Martin-Barbero, que se inscreve na história cultural, marcada pela tradição oral e pela conexão entre os meios de Comunicação e a história específica do continente americano (incluindo nisso a cultura indígena, que é revalorizada). Essas duas abordagens não são incompatíveis, mesmo se aqui nós pendemos mais para a trajetória percorrida por Michel de Certeau na Europa. 
Por outro lado, mesmo se a French Theory teve seu sucesso também na América Latina (Foucault, Barthes, Bourdieu), eu penso que esse momento foi ultrapassado e que as jovens gerações de pesquisadores tendem a se orientar mais por autores americanos (entre outras razões porque os pesquisadores vão fazer doutorado nos Estados Unidos mais do que na Espanha, por exemplo).

Revista Intercom - Em uma de nossas reuniões de trabalho, você me pediu para estar atenta a essa forte crítica que os pesquisadores latinoamericanos tendem a fazer sobre os meios de Comunicação de massa. Neste momento, é possível falar de uma tendência predominante na abordagem europeia sobre os meios massivos? Qual seria ela? Existe um gênero ou um tipo de prática midiática mais abordado atualmente? Lits - Eu acredito que, na Europa, nós saímos progressivamente do modelo de crítica aos meios, que foi construído na linha dos trabalhos da Escola de Frankfurt, de Adorno a Walter Benjamin, e que foi continuado pela Sociologia de Bourdieu. Essa Sociologia Crítica, que impediu uma análise rigorosa do sistema midiático em benefício de discursos ideologicamente carregados a priori ${ }^{3}$, foi deixada a cargo de grupos associativos e militantes. Isto não quer dizer que temos uma visão ingênua sobre as relações entre mídia, poder político e líderes econômicos, mas que nós estimamos que as questões associadas à construção do espaço público são mais complexas que isso ${ }^{4}$. Nós temos tentado também trabalhar com todos os meios de Comunicação e não somente com os jornais de grande reputação ou com os noticiários das grandes redes de televisão. É importante partir dos meios mais consumidos, mas também analisar a imprensa popular, a imprensa regional, as páginas esportivas, as editorias de notícias gerais e a imprensa de celebridades. É nesses espaços que as pessoas constroem sua opinião.

\footnotetext{
${ }^{3}$ Sobre este tema, Lits recomenda a leitura do artigo de Dominique Pasquier, La "culture populaire" à l'épreuve des débats sociologiques, publicado no número 42 da Revista Hermès, em 2005.

${ }^{4}$ Lits desenvolve essa discussão em seu artigo Lespace public: concept fondateur de la communication.
} 
Revista Intercom - No campo das atividades associativas, você participa de atividades promovidas por associações dedicadas ao desenvolvimento da pesquisa em Comunicação? Quais?

Lits - A Bélgica é um país pequeno e, portanto, não tem uma associação nacional. Porém, existe uma união de escolas doutorais de todas as universidades, que organiza todos os anos jornadas doutorais para os jovens pesquisadores. Esse é um fenômeno em franco desenvolvimento. Antes, cada um fazia sua tese sozinho, com seu orientador. Agora, cada universidade, cada país organiza reuniões para jovens pesquisadores, em que se convidam jovens pesquisadores de outros países, algo que promove a circulação desses estudantes e lhes inserem em redes internacionais, que os preparam para um pós-doutorado e lhes dão oportunidades para publicar em revistas estrangeiras. Nós somos todos membros da SFSIC (a Sociedade Francesa de Pesquisadores em Informação e Comunicação, na sigla em francês ${ }^{5}$ ), que reúne a maioria dos pesquisadores francófonos, assim como de uma associação europeia chamada ECREA (a Associação Europeia de Pesquisa e Educação em Comunicação, na sigla em inglês ${ }^{6}$ ), que por sua vez é associada à ICA (a Associação Internacional de Comunicação, na sigla em inglês ${ }^{7}$ ). Essas redes são essenciais para uma pesquisa cada dia mais globalizada. Em paralelo a essas redes, está o engajamento a grupos de pesquisa (por exemplo, o Instituto de Ciências da Comunicação, na sigla em francês ISCC, vinculado ao FNRS - o Fundo Nacional de Pesquisa Científica, na sigla em francês - na França ${ }^{8}$ ) ou a comitês científicos de revistas, o que permite o acompanhamento das descobertas mais recentes. A revista Questions de communication (Questões de Comunicação ${ }^{9}$ ), na recente comemoração de seus dez anos de existência, fez um balanço das pesquisas atuais no campo, assim como a nossa revista da UCL,

\footnotetext{
${ }^{5}$ www.sfsic.org

${ }^{6}$ www.ecrea.eu

${ }^{7}$ www.icahdq.org

${ }^{8}$ www.iscc.cnrs.fr

${ }^{9}$ http://questionsdecommunication.revues.org/
} 
Recherches em communication (Pesquisas em Comunicação ${ }^{10}$ ) havia feito há cerca de dez anos.

Revista Intercom - Qual é a importância dessas associações no desenvolvimento da pesquisa em Comunicação na Europa?

Lits - Essas associações são essenciais, porque o ambiente dos pesquisadores de Comunicação, em cada país, é bastante reduzido, considerando que se trata de uma disciplina jovem, que não se beneficia de grandes contratos de pesquisa atribuídos por grandes empresas e fundos públicos. Sendo assim, as redes internacionais europeias até pouco tempo atrás, e mundiais atualmente, são essenciais, assim como o são para os sociólogos ou cientistas políticos.

Revista Intercom - Qual é o papel de associações internacionais, tais como a ICA (International Communication Association) ou a IAMCR (International Association for Media and Communication Research)? E você poderia mencionar outras associações de abrangência mundial que fazem um bom trabalho nesse campo?

Lits - Como eu disse antes, seu papel é essencial, ainda que o risco dessas grandes associações seja o de não filtrar de maneira suficiente as intervenções em seus colóquios. Assim como acontece em outras comunidades científicas, o tamanho cumpre um papel importante e existe uma tendência a preferir anunciar mil expositores, mesmo se a metade deles não contribui com comunicações originais ou com pesquisas inovadoras. E que não seja possível acompanhar mais do que alguns painéis. A contribuição científica concreta é, portanto, mais limitada do que o anunciado. E é por isso que eu prefiro, pessoalmente, a lógica das redes mais restritas, cuja qualidade eu conheço, em comparação com o modelo de grandes eventos que permitem incorporar algumas linhas mais ao currículo, mas que acabam não contribuindo de forma significativa para o progresso da pesquisa.

${ }^{10}$ http://sites.uclouvain.be/rec/index.php/rec 
Revista Intercom - No que se refere à formação dos pesquisadores, a implementação do Tratado de Bolonha trouxe muitas mudanças para o contexto da pesquisa e para a renovação dos quadros?

Lits - A contribuição principal é dupla, na Bélgica (porque o Tratado de Bolonha não foi implantado da mesma maneira, por exemplo, na França). Primeiro, ele obriga todas as universidades a trabalhar em conjunto para construir percursos de formação doutoral e, portanto, a compartilhar seminários de pesquisa, a organizar jornadas doutorais conjuntas. Os jovens doutorandos não estão mais isolados, eles se encontram com outros pesquisadores iniciantes e experientes. Em seguida, a tese não se limita mais a escrever um trabalho de $\mathrm{PhD}$, porque o doutorado se constitui de uma tese e de uma formação doutoral de 60 créditos. Nesses créditos, uma parte deve ser dedicada à realização da tese em si, mais isso precisa estar associado a seminários de pesquisa, à publicação de artigos, à apresentação de comunicações em colóquios. Existe, portanto, uma aprendizagem real do ofício de pesquisador, com suportes epistemológicos, teóricos e metodológicos, mas também uma formação para a redação de artigos científicos, para a apresentação dessas pesquisas. Isso representa uma verdadeira revolução, em que passamos da situação de pesquisador isolado, sozinho em seu escritório, para um aprendizado progressivo e acompanhado do ofício de jovem pesquisador. Além disso, passou-se a refletir também sobre a valorização do doutorado, seja no contexto da carreira de pesquisador, seja na reconversão para o trabalho em indústrias e empresas.

Revista Intercom - Quando eu me inscrevi para o doutorado na Bélgica, me deparei com a exigência de ter um comitê de acompanhamento, o que foi uma surpresa para mim. Você poderia explicar como funciona essa estrutura e qual é o seu papel na formação doutoral? Lits - O comitê de acompanhamento está também associado à nova organização do doutorado. Primeiro, existe uma comissão que examina a qualidade científica do projeto, antes mesmo que o jovem pesquisador seja autorizado a começar uma tese (não é o orientador que decide sozinho). Em seguida, essa comissão 
designa, em acordo com o orientador e com o doutorando, um comitê de acompanhamento de três ou quatro pessoas, que têm competência reconhecida quanto ao objeto da pesquisa e que vão acompanhar seu desenvolvimento. Esse comitê deve aprovar o projeto no começo (apontando sugestões em relação à metodologia, aconselhando leituras, identificando pistas de pesquisa) e deve rever o doutorando, pelo menos, para a banca de qualificação (no máximo dois anos depois do início da tese). Nesse momento, o doutorando apresenta um relatório detalhado, que pode conter capítulos já escritos, e inclui um plano de trabalho detalhado, mostrando o que foi realizado e o que falta fazer. Há um momento de apresentação oral e um debate semelhante ao que acontece na defesa da tese, em que o doutorando recolhe as observações e tem seu percurso validado, de acordo com suas escolhas metodológicas, seus trabalhos empíricos ou suas pesquisas de campo. Essa etapa permite orientar o doutorando, no caso em que ele esteja seguindo um mau caminho, limitar projetos demasiadamente ambiciosos, e estimular pesquisadoras que possam estar angustiados. Finalmente, esse comitê é a base da banca de defesa do doutorado, sendo ampliado pela contribuição obrigatória de pesquisadores estrangeiros especialistas no tema. 